OPEN ACCESS

Edited by:

Lisa Cunningham, National Institutes of Health (NIH),

USA

Reviewed by:

Ertugrul Kilic,

Istanbul Medipol University, Turkey

Su-Hua Sha,

Medical University of South Carolina,

USA

*Correspondence:

Kelvin Y. Kwan

kwan@dls.rutgers.edu

Received: 08 February 2017 Accepted: 21 April 2017

Published: 18 May 2017

Citation:

Jadali $A$, Ying Y-LM and Kwan $K Y$

(2017) Activation of CHK1 in

Supporting Cells Indirectly Promotes

Hair Cell Survival.

Front. Cell. Neurosci. 11:137.

doi: 10.3389/fncel.2017.00137

\section{Activation of CHK1 in Supporting Cells Indirectly Promotes Hair Cell Survival}

\author{
Azadeh Jadali ${ }^{1,2,3}$, Yu-Lan M. Ying ${ }^{4}$ and Kelvin Y. Kwan ${ }^{1,2 *}$ \\ ${ }^{1}$ Department of Cell Biology and Neuroscience, Rutgers University, Piscataway, NJ, USA, ${ }^{2}$ Stem Cell Research Center and \\ Keck Center for Collaborative Neuroscience, Rutgers University, Piscataway, NJ, USA, ${ }^{3} 3 \mathrm{D}$ Biotek, Bridgewater, NJ, USA, \\ ${ }^{4}$ Department of Otolaryngology - Head and Neck Surgery, Rutgers New Jersey Medical School, Newark, NJ, USA
}

The sensory hair cells of the inner ear are exquisitely sensitive to ototoxic insults. Loss of hair cells after exposure to ototoxic agents causes hearing loss. Chemotherapeutic agents such as cisplatin causes hair cell loss. Cisplatin forms DNA mono-adducts as well as intra- and inter-strand DNA crosslinks. DNA cisplatin adducts are repaired through the DNA damage response. The decision between cell survival and cell death following DNA damage rests on factors that are involved in determining damage tolerance, cell survival and apoptosis. Cisplatin damage on hair cells has been the main focus of many ototoxic studies, yet the effect of cisplatin on supporting cells has been largely ignored. In this study, the effects of DNA damage response in cochlear supporting cells were interrogated. Supporting cells play a major role in the development, maintenance and oto-protection of hair cells. Loss of supporting cells may indirectly affect hair cell survival or maintenance. Activation of the Phosphoinositide 3-Kinase (PI3K) signaling was previously shown to promote hair cell survival. To test whether activating PI3K signaling promotes supporting cell survival after cisplatin damage, cochlear explants from the neural subset (NS) Cre Pten conditional knockout mice were employed. Deletion of Phosphatase and Tensin Homolog (PTEN) activates PI3K signaling in multiple cell types within the cochlea. Supporting cells lacking PTEN showed increased cell survival after cisplatin damage. Supporting cells lacking PTEN also showed increased phosphorylation of Checkpoint Kinase 1 (CHK1) levels after cisplatin damage. Nearest neighbor analysis showed increased numbers of supporting cells with activated PI3K signaling in close proximity to surviving hair cells in cisplatin damaged cochleae. We propose that increased PI3K signaling promotes supporting cell survival through phosphorylation of CHK1 and increased survival of supporting cells indirectly increases hair cell survival after cisplatin damage.

Keywords: cisplatin, ototoxicity, cochlea, supporting cell, cell survival, PI3 kinase signaling, AKT, CHK1

\section{INTRODUCTION}

Sensorineural hearing loss caused by the exposure to loud sounds and ototoxic drugs results in the loss of sensory hair cells and spiral ganglion neurons of the inner ear. Cisplatin is a potent antitumor agent used for its wide clinical activity against many different types of tumors (Wang and Lippard, 2005). A side effect of cisplatin-induced hearing loss is the loss of cochlear hair cells (Rybak et al., 2009; Schacht et al., 2012). Systemic injection of cisplatin results in 
discernable cisplatin-DNA adducts in hair cells and supporting cells that reside in the organ of Corti (van Ruijven et al., 2005). Supporting cells have distinct morphology and specific anatomical locations within the organ of Corti. Dieters' cells reside below the outer hair cells $(\mathrm{OHC})$, inner and outer pillar cells form the tunnel of Corti while Hensen's and Claudius cells are located in the outer sulcus. These cells contribute to the microarchitecture observed in the sensory epithelium (Monzack and Cunningham, 2013; Wan et al., 2013). In addition to maintaining the cytoarchitecture in the cochlea, supporting cells such as inner border cells and inner phalangeal play critical roles in development, maintenance and synaptogenesis of hair cells (Gómez-Casati et al., 2010; Mellado Lagarde et al., 2014). Supporting cells can phagocytose dying hair cells to clear up cellular debris in the sensory epithelium (Bird et al., 2010; Monzack et al., 2015). Supporting cells can protect hair cells from damage by secreting the Heat Shock Protein 70 (HSP70; May et al., 2013). Systemic application of cisplatin shows that supporting cells are structurally damaged and could contribute to delayed hair cell loss (Ramírez-Camacho et al., 2004). Furthermore, after cisplatin damage, phagocytosis of dead hair cells by supporting cells is impaired (Monzack et al., 2015). These studies suggest that supporting cells play distinct cellular roles to maintain proper cochlear function and may be targets of cisplatin damage.

Cytotoxicity after cisplatin exposure is caused by the formation of intra- and inter-strand DNA crosslinks as well as cisplatin DNA adducts (Wang and Lippard, 2005). DNA damage activates several signal transduction pathways that include Ataxia Telangiectasia and Rad3 Related Protein (ATR), p53, p73 and Mitogen-Activated Protein Kinase (MAPK) and results in either cell survival or apoptosis (Siddik, 2003). Checkpoint Kinase 1 (CHK1) is a key downstream target that is phosphorylated by ATR at serine residues 345 and 317 (Zhao and Piwnica-Worms, 2001). Phosphorylation of CHK1 increases kinase activity and initiates the DNA damage response by activating DNA damage repair, DNA damage checkpoints and cell death proteins (Zhang and Hunter, 2014). DNA damagemediated apoptotic signals can be attenuated as observed in cisplatin resistant tumor cells. Cisplatin resistant cancer cells arise when propagation of the DNA damage signal to the apoptotic machinery is inhibited. These mechanisms include activation of the Phosphoinositide 3-Kinase (PI3K)/RAC-Alpha Serine Threonine Protein Kinase (PI3K/AKT) signaling, loss of p53 function and overexpression of anti-apoptotic factors such as B-cell leukemia/lymphoma 2 (BCL2) to promote cell survival (Siddik, 2003). In this study, we determined whether phosphorylation of CHK1 promotes cochlear supporting cell survival after cisplatin damage.

\section{MATERIALS AND METHODS}

\section{Cell Culture}

Immortalized multipotent otic progenitor (iMOP) cells were grown in suspension with DMEM/F12 (Life Technologies) containing B27 supplement (Life Technologies), $25 \mu \mathrm{g} / \mathrm{ml}$ carbenicillin and $20 \mathrm{ng} / \mathrm{ml}$ basic fibroblast growth factor (bFGF; Pepro Tech; Jadali et al., 2016). For differentiation experiments, cells were cultured for 3 or 7 days in the absence of bFGF depending on the experiment. iMOP cells were treated with LY294002 (LC laboratories), bpV(Hopic; Santa Cruz Biotechnology, Inc., Santa Cruz, CA, USA) or cisplatin (Sigma) at the specified concentrations. LY294002 and bpV(Hopic) were solubilized in dimethyl sulfoxide (DMSO) and added to medium as described. Cisplatin was dissolved into medium and warmed to $37^{\circ} \mathrm{C}$ to make a $1 \mathrm{mM}$ stock solution. Cisplatin solution was diluted into culture medium at the described concentrations.

\section{Proliferation and EdU Incorporation Assays}

For 5-ethynyl-2'-deoxyuridine (EdU) labeling, the Click-iT EdU Alexa Fluor 488 assay kit (Life Technologies) was used. iMOP cells were pulsed with $1 \mu \mathrm{M}$ EdU for $2 \mathrm{~h}$. After EdU incorporation, cells were removed from culture, dissociated to generate single cells, fixed, labeled EdU with Alexafluor 488 by click chemistry, resuspended in $1 \times$ PBS containing $0.1 \%$ Tween 20 and mounted on a slide. Fluorescent images of labeled cells were taken using epifluorescence microscopy and the percentage of EdU positive cells in 1000 nuclei was determined.

\section{Flow Cytometry and Apoptosis Assay}

iMOP cells were differentiated for 3 days before they were treated with $50 \mu \mathrm{M}$ cisplatin alone, or pre-treated with $25 \mu \mathrm{M}$ LY294002 or $10 \mu \mathrm{M}$ bpV(HOpic) for $1 \mathrm{~h}$ before treatment with $50 \mu \mathrm{M}$ cisplatin. Apoptotic cells were analyzed $24 \mathrm{~h}$ after treatment with small molecules. To identify apoptotic cells, the Alexa Fluor 488 annexin V/PI dead cell apoptosis kit was used (Life Technologies) according to manufacturer's instructions. Cells labeled with Alexa Fluor 488 annexin V and/or PI and were quantified by flow cytometry using a Beckman Coulter Gallios flow cytometer with the appropriate filters.

\section{Western Blot Analysis}

Cells were lysed in lysis buffer $(50 \mathrm{mM}$ Tris/ $\mathrm{HCl}, \mathrm{pH} 7.5$, $150 \mathrm{mM} \mathrm{NaCl}, 1 \mathrm{mM}$ EDTA, $1 \mathrm{mM}$ EGTA, 1\% Triton $\mathrm{X}-100$, and $10 \%$ glycerol containing phosphatase inhibitor (Thermo Scientific) and a mixture of protease inhibitors (Roche). Protein lysates $(30 \mu \mathrm{g})$ were loaded and separated on $4 \%-12 \%$ Bis Tris Novax NuPAGE gradient gels (Life Technologies), transferred to PVDF membrane, and incubated in blocking buffer (phosphate-buffered saline (PBS), 0.1\% Tween 20 and $5 \%$ nonfat dried milk) for $1 \mathrm{~h}$. To detect proteins of interest, membranes were incubated overnight at $4^{\circ} \mathrm{C}$ with primary antibodies. Immunoreactive bands were detected by incubating with horseradish peroxidase-conjugated secondary antibodies, followed by application of chemiluminescence substrate (Pierce ECL, Thermo Fisher Scientific). Membranes were exposed to either X-ray film (RPI) or Amersham Hyperfilm ECL (GE Healthcare) for signal detection before film development. To detect multiple proteins using the same membrane, membranes were stripped and re-probed with the 
TABLE 1 | Antibodies and Small Molecules.

\begin{tabular}{|c|c|c|c|}
\hline Antibody/Small molecule & Company & Use & Dilution \\
\hline AKT & Cell Signaling Technologies & Western blot & $1: 3000 / 1: 1000$ \\
\hline pAKT-Thr308 & Cell Signaling Technologies & Western blot & $1: 1000$ \\
\hline $\mathrm{CHK} 1$ & Cell Signaling Technologies & Western blot & $1: 1000$ \\
\hline pCHK1-Ser345 & Cell Signaling Technologies & Western blot/Immunostaining & $1: 1000 / 1: 100$ \\
\hline ACTB & Santa Cruz Biotechnology & Western blot & $1: 1000$ \\
\hline MYO7A & Proteus & Immunostaining & $1: 1000$ \\
\hline Phalloidin-Alexafluor 647 & Life Technologies & Immunostaining & $1: 400$ \\
\hline
\end{tabular}

appropriate primary antibodies. Quantification of the intensity from individual bands was done using Photoshop. Antibodies and dilutions of antibodies for Western blot are described in Table 1.

\section{Cochlear Explant Cultures}

Cochleae from P4-6 pups were dissected and cleaned of surrounding tissue and bone. The stria vascularis was trimmed and the Reissner's and the tectorial membrane peeled away to expose the sensory epithelium. To ensure that the explanted cochlea adhered to the bottom of the coverglass, the cochlea was cut into three individual pieces and adhered onto a 1.5 cover glass treated with $10 \mu \mathrm{g} / \mathrm{ml}$ poly-L-ornithine. Cochlear explants were cultured in DMEM/F12 containing $10 \%$ FBS, $2 \mathrm{mM}$ L-Glutamine and $25 \mu \mathrm{g} / \mathrm{ml}$ carbenicillin. One day after plating, cochleae were treated with either $10 \mu \mathrm{M}$ bpV(HOpic) or DMSO before addition of $20 \mu \mathrm{M}$ cisplatin. Hair cells counts per $200 \mu \mathrm{m}$ were divided into base, middle and apical regions of the cochlear explants and used to determine the percent of surviving hair cells along the tonotopic axis.

\section{Immunofluorescence Staining}

Conditions used for immunostaining of iMOP cells were previously described (Kwan et al., 2015). Cochlear explants were fixed in $4 \%$ formaldehyde with $1 \times$ PBS for $1 \mathrm{~h}$, permeabilized in wash buffer (PBS and $0.1 \%$ Triton X-100) for $10 \mathrm{~min}$, incubated in blocking buffer (PBS, $10 \%$ goat serum and $0.1 \%$ Triton $\mathrm{X}-100$ ) for $1 \mathrm{~h}$ and incubated overnight with a 1:500 dilution of Myosin 7A (MYO7A; Proteus Biosciences) primary antibody in blocking buffer. For CHK1 labeling, antigen retrieval was accomplished by incubating fixed cochlea in $150 \mathrm{mM}$ Tris- $\mathrm{HCl}$ at $\mathrm{pH} 9.0$ for $5 \mathrm{~min}$, followed by heating at $70^{\circ} \mathrm{C}$ for $15 \mathrm{~min}$. Cochleae were rinsed in wash buffer before incubating overnight with a 1:100 dilution of pCHK1 (Cell Signaling) antibodies in blocking buffer. Detection of primary antibodies was done by removing the primary antibody solutions and washing the cochleae in wash buffer three times before incubating in 1:500 dilution of goat anti-rabbit Alexa Fluor 488 secondary antibody and 1:500 phalloidin Alexa Fluor 647 (Life Technologies) in blocking buffer for $2 \mathrm{~h}$. Cochleae were rinsed and mounted on slides with prolong gold antifade mounting media (Life Technologies). Immunofluorescence images were obtained using a Zeiss 510 confocal microscope with a $40 \times 1.3 \mathrm{NA}$ water immersion objective. The average percent of MYO7A positive inner hair cells (IHC) and OHC were obtained by calculating the percentage of MYO7A cells along the cochlear axis from treated cochlear explants relative to untreated controls. Antibodies and dilutions of antibodies for immunostaining are described in Table 1.

\section{Biohazardous Material}

All biohazardous material such as LY294002, bpV (HOpic) and cisplatin were handled in a laminar flow hood and appropriately disposed after usage as recommended by Rutgers Environmental Health and Safety (REHS).

\section{Animals}

All mice were housed in the Nelson Labs animal facility in microisolator cages. Neural subset (NS) Cre PTEN mice in the B6;129S4 genetic background were previously described (Jadali and Kwan, 2016). This study was carried out in accordance with the recommendations of the Rutgers Animal Care and Facilities Committee (ACFC). The protocol was approved by the Rutgers University Institutional Animal Care and Use Committee (IACUC).

\section{Statistical Analysis}

All error bars shown in data are expressed as \pm standard deviation (SD) of values obtained from independent experiments unless otherwise stated. The numbers $(n)$ of independent experiments or individual wells from separate cultures are listed for experiments. Technical triplicates were included in each experiment. An unpaired two-tailed Student's $t$-test was used to determine statistical significance and associated with the appropriate $p$ value. For all figures $p$ values are defines as: ${ }^{*} p<0.05,{ }^{* *} p<1 \times 10^{-2},{ }^{* * *} p<1 \times 10^{-3}$ and ${ }^{* * * *} p<1 \times 10^{-4}$ unless otherwise stated.

\section{RESULTS}

\section{Differentiating iMOP Cells Express Hair Cell and Supporting Cell Markers}

To identify signaling pathways that maintain hair cell survival, we used iMOP cells that can self-renew and differentiate into hair cells and supporting cells (Kwan et al., 2015). Differentiating iMOP cells were generated by withdrawing bFGF for 7 days, to promote cell cycle exit and differentiation (Jadali et al., 2016). To determine the proliferative capacity of proliferating or differentiating iMOP cultures, incorporation of the nucleotide analog EdU was used. As iMOP cells progress through the cell cycle and undergo DNA replication, EdU was incorporated into the DNA. Incorporation of EdU 
provides an index for proliferation. Proliferating iMOP cells and differentiating iMOP cells normally grow as clusters of cells, or otospheres. To allow for unambiguous cell counts, otospheres from iMOP cultures were dissociated, fixed and labeled with Hoechst after EdU incorporation. Proliferating iMOP cells showed EdU labeling in $37.9 \% \pm 2.5$ of Hoechst labeled nuclei (Figure 1A). Differentiating iMOP cells showed EdU labeling in $3.3 \% \pm 1.2$ of Hoechst labeled nuclei (Figure 1B). A significant 11.5 fold reduction $\left(p<1 \times 10^{-4}\right)$ in cells that have undergone DNA replication was observed in differentiating cells compared to proliferating cells. These results suggest that the vast majority of differentiating

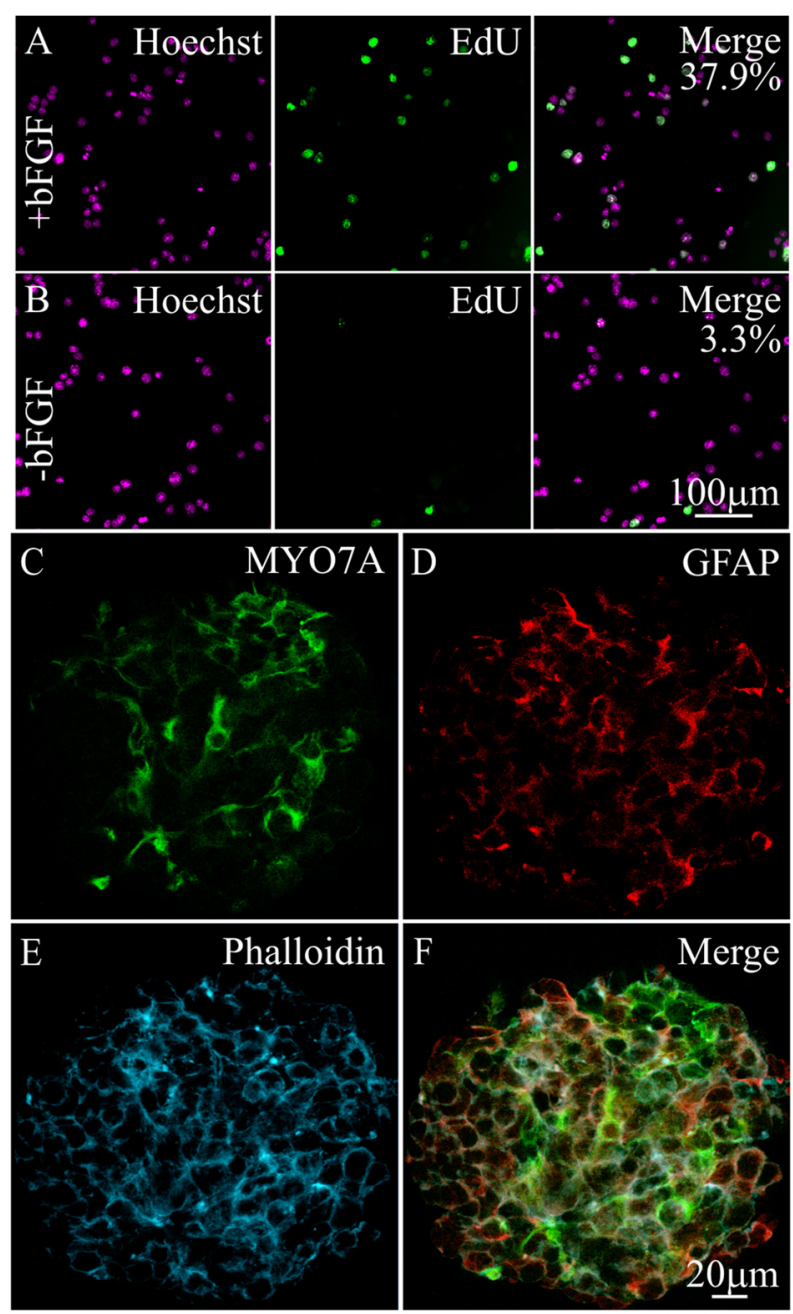

FIGURE 1 | Expression of hair cell and supporting cell markers in differentiating immortalized multipotent otic progenitor (iMOP) cells. Proliferating iMOP cells cultured in basic fibroblast growth factor (bFGF) were subjected to 5-ethynyl-2'-deoxyuridine (EdU) incorporation. (A) Hoechst labeled nuclei from proliferating iMOP cells show EdU incorporation in 37.9\% of cells $(n=3)$. (B) Hoechst labeled nuclei from differentiating iMOP cells showed EdU incorporation in $3.3 \%$ of cells $(n=3)$. Differentiating iMOP cells express (C) MYO7A and (D) glial fibrillary acidic protein (GFAP) in (E) phalloidin marked otospheres. (F) Otospheres from differentiating iMOP cultures were used to test for the effects of cisplatin treatment.
iMOP cells were no longer progressing through the cell cycle.

To determine the extent of differentiation, otospheres from differentiating iMOP cultures were harvested, fixed and immmunostained with antibodies against MYO7A, a hair cell marker and glial fibrillary acidic protein (GFAP), a supporting cell marker. Differentiating iMOP cells showed MYO7A (Figure 1C) and GFAP (Figure 1D) labeling. Otospheres from differentiating iMOP cells also showed circumferential actin after phalloidin labeling (Figure 1E) that was reminiscent of actin filament distribution in the developing cochlea sensory epithelium. Differentiating iMOP cultures containing MYO7A and GFAP expressing cells were subsequently employed as a cellular platform to study the effects of cisplatin damage in hair cells and supporting cells (Figure 1F).

\section{Activation of PI3K Promotes iMOP Cell Survival after Cisplatin Damage}

Since PI3K signaling has been implicated in maintaining hair cell survival after aminoglycoside damage (Chung et al., 2006; Jadali and Kwan, 2016), we determined whether PI3K signaling was also involved in promoting supporting cell survival after cisplatin damage. To test how PI3K signaling affects cell survival, differentiating iMOP cells were treated with small molecules that activated or inhibited PI3K signaling. To activate PI3K/AKT signaling, we used the small molecule $\mathrm{bpV}(\mathrm{HO}$ pic) that inhibits phosphatase tension homolog deleted on chromosome 10 $(P T E N)$ and increase phosphatidylinositol-3,4,5-trisphosphate $\left(\mathrm{PIP}_{3}\right)$ levels. Excess $\mathrm{PIP}_{3}$ at the cell membrane increases PI3K signaling (Cantley and Neel, 1999; Doillon et al., 1999; Schmid et al., 2004). As a control, the small molecule LY294002 was used as an inhibitor of PI3K activity (Vlahos et al., 1994). The concentrations of small molecules employed was previously identified from dose response curves (Jadali and Kwan, 2016). Activator or inhibitor of PI3K signaling was added before cisplatin-induced damage in differentiating iMOP cells and apoptotic cells were quantified by flow cytometry analysis. Differentiating iMOP cells were treated with cisplatin, harvested and subjected to dual labeling with propidium iodide (PI) and Alexafluor 488-conjugated annexin V. Treated samples were compared to DMSO treated controls. FACS analysis was employed to identify apoptotic cells labeled with PI and apoptotic marker annexin V (Vermes et al., 1995). The percentage of viable cells (PI- annexin V) in the lower left quadrant and the apoptotic cells (PI+ annexin $\mathrm{V}+$ ) in the upper right quadrant of the FACS plot were quantified. In control, $64.2 \%$ viable cells and $28.7 \%$ apoptotic cells were observed (Figure 2A). Treatment with $50 \mu \mathrm{M}$ cisplatin in differentiating iMOP cells resulted in $26.4 \%$ viable cells and $68.1 \%$ apoptotic cells (Figure 2B). These results suggest an increase in apoptotic cells after cisplatin treatment.

To test whether activation of the PI3K pathway would promote cell survival after cisplatin treatment, differentiating iMOP cells were cultured with $10 \mu \mathrm{M}$ of $\mathrm{bpV}(\mathrm{HOpic})$ for 1 day before cisplatin treatment. Pre-treatment with bpV(HOpic) 

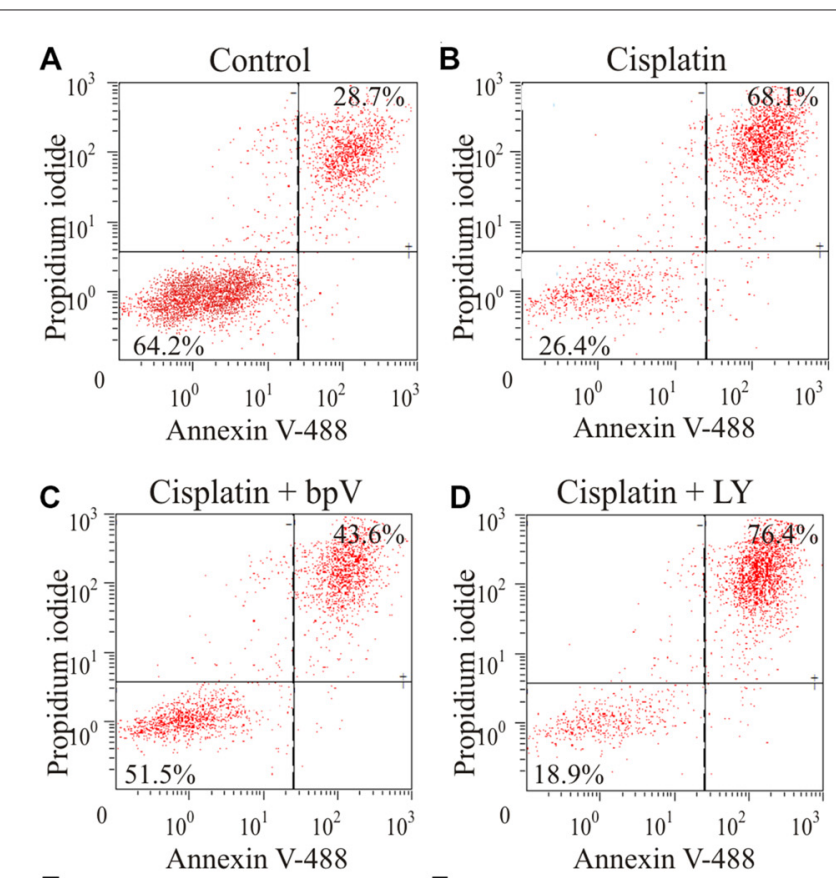

E
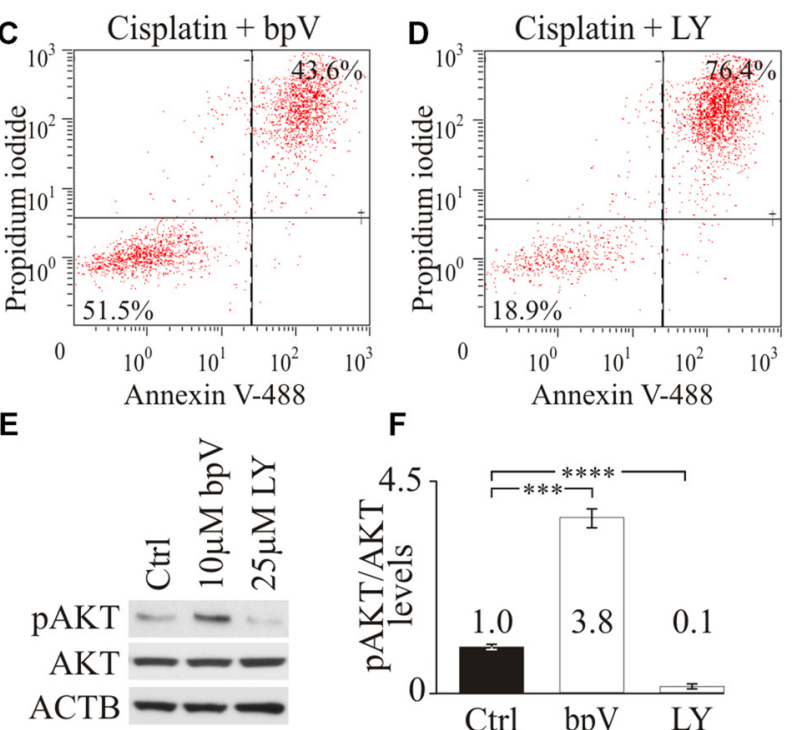

\section{$F$}
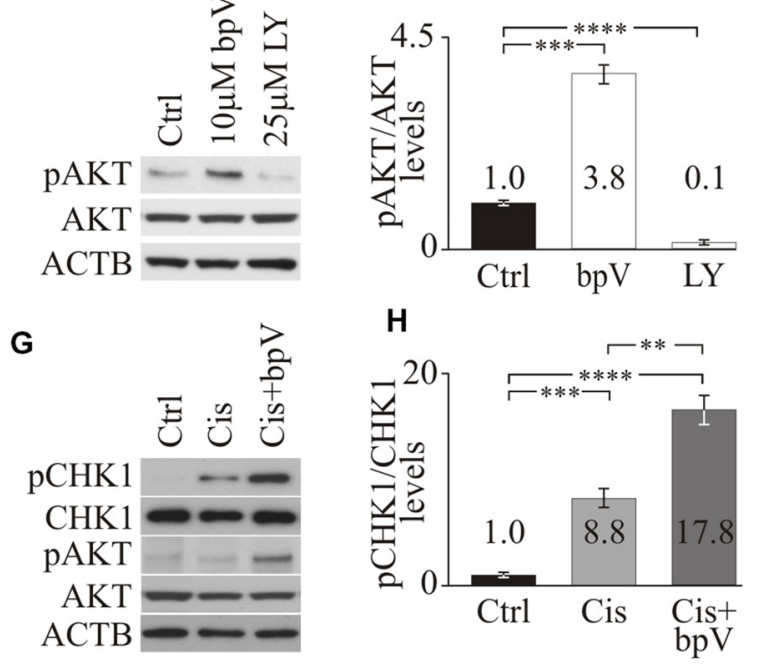

FIGURE 2 | Checkpoint Kinase 1 (CHK1) phosphorylation after activating phosphoinositide 3-kinase (PI3K) signaling. Propidium iodide (PI) and annexin V FACS analysis of (A) control dimethyl sulfoxide (DMSO),

(B) cisplatin (C) cisplatin and bpV(HOpic) and (D) cisplatin and LY treated cells from representative plots. Average percentage of cells from viable (PIannexin $\mathrm{V}$-) and apoptotic ( $\mathrm{Pl}+$ annexin $\mathrm{V}+$ ) quandrants were displayed $(n=4)$. (E) Western blot of phospho-AKT (pAKT), total AKT and ACTB in control DMSO, $10 \mu \mathrm{M}$ bpV(HOpic) or $25 \mu \mathrm{M}$ LY294002 treated cells $(n=4)$. (F) Quantification of pAKT/AKT ratio from Western blots $(n=4)$. (G) Western blot of pCHK1, total phospho-CHK1 (CHK1), pAKT, total AKT and ACTB in control DMSO, $20 \mu \mathrm{M}$ cisplatin, $20 \mu \mathrm{M}$ cisplatin and $10 \mu \mathrm{M}$ bpV(HOpic) treated cells $(n=4)$. (H) Quantification of $\mathrm{pCHK1/CHK1} \mathrm{ratios} \mathrm{from} \mathrm{Western}$ blots $(n=4)$. Statistical significance was determined using the Student's $t$-test and error bars are in standard deviation (SD).

resulted in $51.5 \%$ viable cells and $43.6 \%$ apoptotic cells (Figure 2C). Compared to cisplatin treatment alone, addition of $\mathrm{bpV}(\mathrm{HOpic})$ increased the percentage of viable cells. These results suggested that addition of $\mathrm{bpV}(\mathrm{HOpic})$ promotes cell survival even after exposure to cisplatin. To implicate the role of PI3K signaling in cell survival, LY294002, an inhibitor for PI3K activity was used. Differentiating iMOP cells were pretreated with $25 \mu \mathrm{M}$ LY294002 before cisplatin treatment resulted in $18.9 \%$ viable cells and $76.4 \%$ apoptotic cells (Figure 2D). Inhibition of PI3K signaling increased the percentage of apoptotic cells. Together, these results suggest that activation of the PI3K signaling pathway may attenuate apoptosis and promote cell survival in differentiating iMOP cells.

\section{Activation of PI3K Increases CHK1 Phosphorylation after Cisplatin Damage}

To ensure that small molecules had the appropriate effect on PI3K signaling, phosphorylated RAC-alpha serine/threonine protein kinase (AKT) levels were employed as a measure of PI3K signaling activity. Western blot for phospho-AKT (pAKT), AKT and $\beta$-Actin (ACTB) was performed on cell lysates obtained from untreated control, $10 \mu \mathrm{M} \mathrm{bpV}(\mathrm{HOpic})$ treated and $25 \mu \mathrm{M}$ LY294002 treated differentiating iMOP cultures (Figure 2E). ACTB served as a loading control. To quantify the amount of pAKT and total AKT, Western blot signals from the appropriate bands were quantified and the ratio of pAKT to AKT levels was determined. Signals were then normalized to untreated control and presented as fold change. After treatment with $10 \mu \mathrm{M}$ bpV(HOpic), a significant $3.8 \pm 0.32$ fold increase in normalized $\mathrm{pAKT}$ levels was observed compared to control $\left(p<1 \times 10^{-3}\right)$. Treatment of differentiating iMOP cells with $25 \mu$ M LY294002 showed a significant $10 \pm 0.02$ fold decrease in normalized pAKT levels compared to control $\left(p<1 \times 10^{-4}\right.$; Figure 2F). These results suggested that $10 \mu \mathrm{M} \mathrm{bpV(HOpic)} \mathrm{and}$ $25 \mu \mathrm{M}$ LY294002 can be used to activate or inhibit PI3K signaling respectively in differentiating iMOP cells.

Following cisplatin damage, $\mathrm{CHK} 1$, an evolutionarily conserved protein kinase that regulates DNA damage repair is phosphorylated and activated by ATR (Zhao and PiwnicaWorms, 2001). ATR phosphorylates CHK1 at serine residues 317 and 345 in response to DNA damage (Zhao and PiwnicaWorms, 2001). Phosphorylation of CHK1 at Ser345 serves to localize CHK1 to the nucleus following DNA damage checkpoint activation (Jiang et al., 2003). To determine the effects of PI3K signaling in DNA damage response in differentiating iMOP cells, phosphorylation of CHK1 at Ser345 was determined by Western blot using phospho-specific antibodies. Differentiating iMOP cultures were treated with cisplatin to determine if phospho-CHK1 (pCHK1) levels increased relative to untreated control. To promote cell survival and determine the effects of activating PI3K signaling on pCHK1 levels, differentiating iMOP cultures were pretreated with $10 \mu \mathrm{M}$ bpV(HOpic) before inducing cisplatin damage. Lysates from iMOP cultures were collected and used for Western blot analysis. ACTB was used as a loading control (Figure 2G). The ratio of $\mathrm{pCHK} 1$ and total CHK1 were used to determine normalized pCHK1 levels and represent the extent of DNA damage response. After 
treatment with $10 \mu \mathrm{M}$ cisplatin alone, a significant $8.8 \pm 1.0$ fold increase in normalized pCHK1 levels was observed compared to untreated control $\left(p<1 \times 10^{-3}\right.$; Figure $\left.2 \mathbf{H}\right)$. This suggests that cisplatin damage of differentiating iMOP cells activated the DNA damage response. To determine if activation of PI3K signaling alters pCHK1 levels, differentiating iMOP cultures were pretreated with bpV(HOpic) before cisplatin. Normalized pAKT levels were used as a measure of PI3K signaling activity. As observed in the Western blot, addition of $\mathrm{bpV}$ (HOpic) increased normalized pAKT levels $3.2 \pm 0.2$ fold relative to untreated control and increased $3.5 \pm 0.5$ fold relative to cisplatin treated cultures (Figure 2G). These results suggest that addition of $\mathrm{bpV}(\mathrm{HOpic})$ activates $\mathrm{PI} 3 \mathrm{~K}$ signaling. Pretreating iMOP cells with $10 \mu \mathrm{M}$ bpV(HOpic) before incubating in $10 \mu \mathrm{M}$ cisplatin resulted in a significant increase in pCHK1 levels (Figure 2G). Quantification of the Western blot showed a $17.8 \pm 1.5$ fold increase in normalized pCHK1 levels compared to untreated control $\left(p<1 \times 10^{-4}\right.$; Figure $2 \mathbf{H}$ ). Comparing cisplatin treated sample to bpV(HOpic) and cisplatin treated samples, a significant 2.0 fold increase in normalized pCHK1 levels was observed $\left(p<1 \times 10^{-2}\right.$; Figure $2 \mathbf{H}$ ). The results suggest that activation of PI3K signaling increases phosphorylation of CHK1 after cisplatin damage and could promote survival of differentiating iMOP cells.

\section{Activation of PI3K Signaling Using bpV(HOpic) Promotes Hair Cell Survival after Cisplatin Damage}

The above results suggested that activation of PI3K signaling could enhance CHK1 phosphorylation and promote a DNA damage response to increase cell survival. We previously showed that activation of PI3K signaling could promote hair cell survival (Jadali and Kwan, 2016). We wanted to extend our findings and determine if activation of the PI3K signaling can promote supporting cell survival in the cochlea when subjected to ototoxic damage. Since hair cell survival may depend on the oto-protective effect and maintenance of supporting cells (May et al., 2013; Mellado Lagarde et al., 2014), we used hair cells counts and hair cell organization as an indirect indicator for the presence of supporting cells after challenging cochlea explants with cisplatin.

To induce cochlear damage, murine cochlear explants were exposed to cisplatin. Cochleas were obtained from early post-natal day (P) 4-6 mice and cultured for a day to allow for recovery before addition of $10 \mu \mathrm{M} b \mathrm{bV}$ (HOpic). After $\mathrm{bpV}(\mathrm{HOpic})$ treatment, cochleae were exposed to $20 \mu \mathrm{M}$ of cisplatin for $24 \mathrm{~h}$ before cisplatin and bpV(HOpic) were removed. Fresh medium without cisplatin or bpV(HOpic) was added to the cochlear cultures. The cochlear explants were allowed to recover for an additional 3 days, fixed and subjected to immunostaining (Figure 3A). Cochleae were immmunostained with antibodies against MYO7A to label IHC and OHC bodies while phalloidin highlighted the actin filled hair bundles and the actin filaments in the sensory epithelium (Figure 3B). In control untreated cochlear explants, the typical one row of IHC and
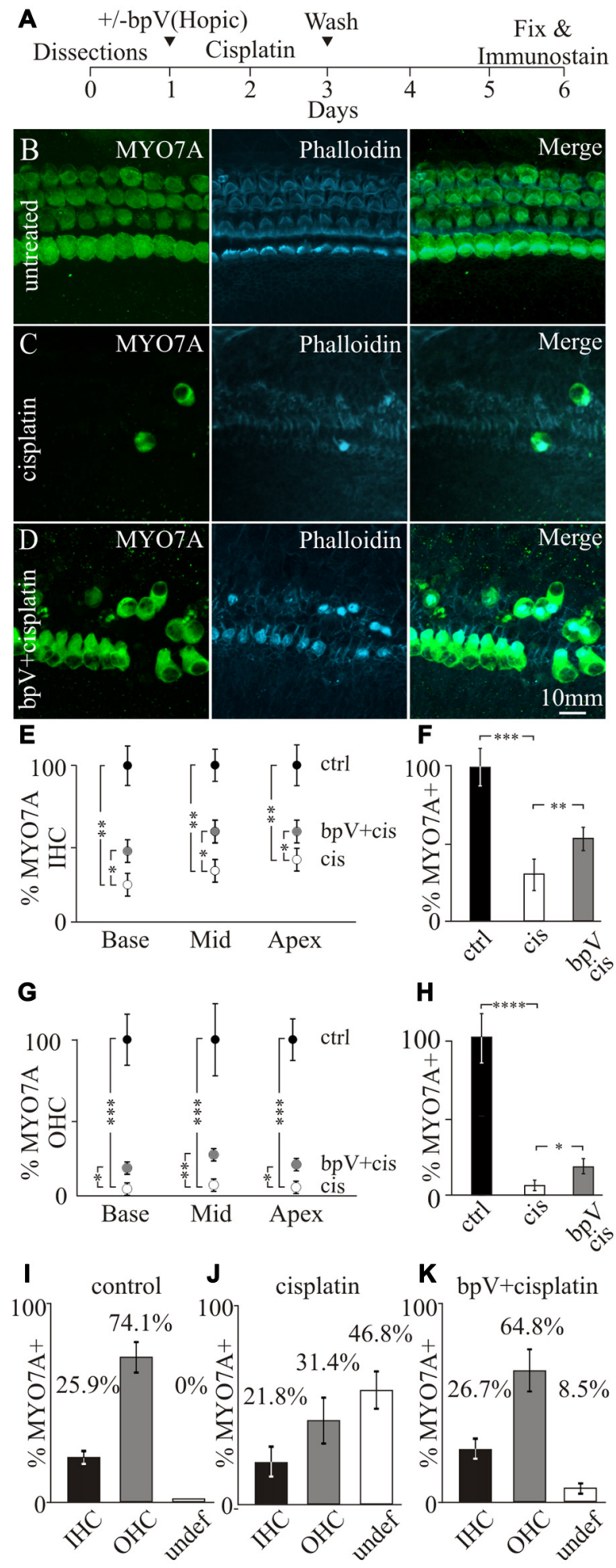

FIGURE 3 | Effects of bpV(HOpic) on hair cell survival after cisplatin damage. (A) Timeline of cochlear explant cultures describing the addition of $10 \mu \mathrm{M}$ bpV(HOpic) 1 day before $10 \mu \mathrm{M}$ cisplatin treatment and harvesting of explants for immunostaining. Immunofluorescence of MYO7A, phalloidin and merged images from (B) control cochlear explant $(n=4)$, (C) cochlear explant treated with cisplatin $(n=4)$ and $(\mathbf{D})$ cochlear explant pretreated with

(Continued) 


\section{FIGURE 3 | Continued}

$10 \mu \mathrm{M}$ bpV(HOpic) before cisplatin damage $(n=4)$. (E) Quantification of MYO7A inner hair cells $(\mathrm{IHC})$ from the basal, middle and apical regions of cochlea explants in control (black), cisplatin (white) and bpV(HOpic)/cisplatin (gray; $n=4)$. (F) Average percent of $\mathrm{IHC}$ in control (black; $n=4)$, cisplatin (white; $n=4$ ) and bpV(HOpic) and cisplatin (gray; $n=4$ ) treated explants normalized to control. (G) Percentage of MYO7A outer hair cells $(\mathrm{OHC})$ in control (black; $n=4)$, bpV(HOpic) and cisplatin (gray; $n=4$ ) and cisplatin treated (white; $n=4$ ) cochlear explants from the basal, middle and apical regions. (H) Average percent of $\mathrm{OHC}$ from control (black; $n=4$ ), cisplatin (white; $n=4$ ) and bpV(HOpic) and cisplatin (gray; $n=4$ ) treated explants. Percentage of surviving $\mathrm{IHC}, \mathrm{OHC}$ and undefined hair cells in (I) control, (J) cisplatin and (K) bpV(HOpic) and cisplatin treated cochlear explants. Statistical significance was determined using the Student's $t$-test and error bars are in SD.

three rows of OHC could be observed. The two types of hair cells are separated by the tunnel of Corti formed by inner and outer pillar cells. The heads of the pillar cells converge on the surface of the sensory epithelium and can be seen as phalloidin labeling between the IHCs and the first row of OHCs (Figure 3B). IHCs and OHCs were defined by their relative location to the heads of the pillar cells. Treatment of cochlear cultures with 20 $\mu \mathrm{M}$ cisplatin for $24 \mathrm{~h}$ resulted in the lack of MYO7A labeled hair cell bodies in the sensory epithelium along with the loss of phalloidin marked hair bundles (Figure 3C). Due to the disruption in the microarchitecture of the sensory epithelium, it was sometimes difficult to distinguish between IHCs and OHCs. Pretreatment of cochlear explants with $10 \mu \mathrm{M} b \mathrm{bp}$ (HOpic) displayed increased numbers of surviving MYO7A labeled hair cells with phalloidin marked hair bundles (Figure 3D). In some regions, the IHC and $\mathrm{OHC}$ organization could still be discerned.

Since cisplatin-induced toxicity has different effects on IHC and OHCs (Schacht et al., 2012), the percentages of the two different types of hair cells were separately quantified. Surviving IHCs and OHCs were distinguished based on their location relative to where the heads of the pillar cells were located. To determine the effects of IHC and OHC survival after bpV(HOpic) treatment, hair cells were counted along the length of the cochlea. The cochlea was partitioned into three segments, the base, middle and the apex. Surviving hair cells were then represented as a percentage of MYO7A labeled hair cells relative to untreated samples. Treatment of cisplatin showed a significant reduction of MYO7A labeled IHCs along the length of the cochlea relative to controls. The percentage of IHCs after cisplatin damage significantly dropped from $100 \%$ to $23.0 \pm 5.2 \%$ in the base $\left(p<1 \times 10^{-2}\right), 32.3 \pm 6.6 \%$ in the middle $\left(p<1 \times 10^{-2}\right)$ and $40.1 \pm 5.7 \%$ in the apex $\left(p<1 \times 10^{-2}\right)$. After pretreatment with bpV(HOpic), the percentage of surviving IHCs compared to cisplatin treatment alone significantly increased to $44.8 \pm 4.8 \%$ in the base $(p<0.05), 58.1 \pm 6.5 \%$ in the middle $(p<0.05)$ and $56.8 \pm 5.2 \%$ in the apex $(p<0.05$; Figure 3E). On average, cisplatin treatment significantly decreased IHC levels from $100 \pm 9.5 \%$ to $32.0 \pm 4.4 \%\left(p<1 \times 10^{-3}\right)$. Before cisplatin treatment, addition of $\mathrm{bpV}(\mathrm{HOpic})$ significantly increased the percentage of IHCs to $53.3 \pm 4.2 \%\left(p<1 \times 10^{-2}\right.$;
Figure 3F). These results suggest that addition of $\mathrm{bpV}$ (HOpic) and activation of PI3K signaling increases IHC survival after cisplatin damage.

For OHCs, addition of cisplatin significantly decreased the percentage of MYO7A labeled OHCs from $100 \%$ to $3.7 \pm 1.0 \%$ in the base, $6.7 \pm 0.9 \%$ in the middle and $5.2 \pm 1.3 \%$ in the apex. Pretreatment with $\mathrm{bpV}(\mathrm{HOpic})$ increased the percentage of surviving $\mathrm{OHCs}$ to $11.8 \pm 2.8 \%$ in the base $(p<0.05)$, $20.2 \pm 2.9 \%$ in the middle $\left(p<1 \times 10^{-2}\right)$ and $16.1 \pm 2.8 \%$ in the apex $(p<0.05$; Figure 3G). On average, cisplatin treatment significantly decreased percentage of OHCs from $100 \pm 13.9 \%$ to $5.2 \pm 1.94 \%\left(p<1 \times 10^{-4}\right)$, while the addition of bpV(HOpic) significantly increased the percentage to $16.2 \pm 2.7 \%(p<0.05$; Figure $3 \mathrm{H})$. Although bpV(HOpic) promoted OHC survival, $\mathrm{OHC}$ loss was still more prominent than IHC loss as previously described (Schacht et al., 2012). Our results demonstrate that activation of PI3K signaling using bpV(HOpic) can increase both IHC and $\mathrm{OHC}$ survival after cisplatin-induced damage.

In addition to hair cell loss, we noticed that the microarchitecture of the sensory epithelium was altered and typical hair cell organization was disrupted. Some hair cells could not be unambiguously characterized as IHCs or OHCs. To quantify this effect, surviving IHCs or OHCs were characterized based on their location to the heads of pillar cells. Hair cells that could not be categorized were labeled as undefined. In untreated cells, $25.9 \pm 1.5 \%$ and $74.1 \pm 6.1 \%$ of hair cells corresponded to IHCs and OHCs respectively while no undefined hair cells were observed (Figure 3I). These percentages correlate well with the proportion of $1 \mathrm{IHC}$ to $3 \mathrm{OHCs}$ that are normally present in the cochlea. Treatment of cisplatin resulted in $21.8 \pm 5.9 \%$ IHCs, $31.4 \pm 8.5 \%$ OHCs with a large population, $46.8 \pm 9.3 \%$ of undefined hair cells (Figure 3J). Addition of bpV(HOpic) before treatment with cisplatin resulted in $26.7 \pm 3.8 \%$ IHCs, $64.8 \pm 19.6 \%$ OHCs and $8.5 \pm 2.8 \%$ undefined hair cells (Figure 3K). The data suggest that application of bpV(HOpic) to cochlear cultures could activate PI3K signaling in multiple cell types including supporting cells. After activating PI3K signaling, the cochlear cytoarchitecture is maintained in some regions of the sensory epithelium where IHCs can be distinguished from OHCs even after cisplatin damage. We hypothesize that activation of PI3K signaling increases survival of supporting cells by increasing CHK1 activity. Increased supporting cell survival helps provide oto-protection and maintain hair cell organization after cisplatin damage. To directly address whether activation of PI3K signaling increases phosphorylation of $\mathrm{CHK} 1$ promotes supporting cells survival after cisplatin damage, a genetic approach was employed.

\section{Genetic Activation of PI3K Signaling in Supporting Cells}

To genetically activate PI3K signaling, a Pten conditional knock out mouse model was used. PTEN normally dephosphorylates $\mathrm{PIP}_{3}$ to $\mathrm{PIP}_{2}$ and by ablating the Pten gene, $\mathrm{PIP}_{3}$ levels increase to activate PI3K signaling (Cantley and Neel, 1999). To target cochlear cell types for Cre mediated excision of Pten, we used a neuronal-subset (NS) Cre recombinase mouse that was generated 


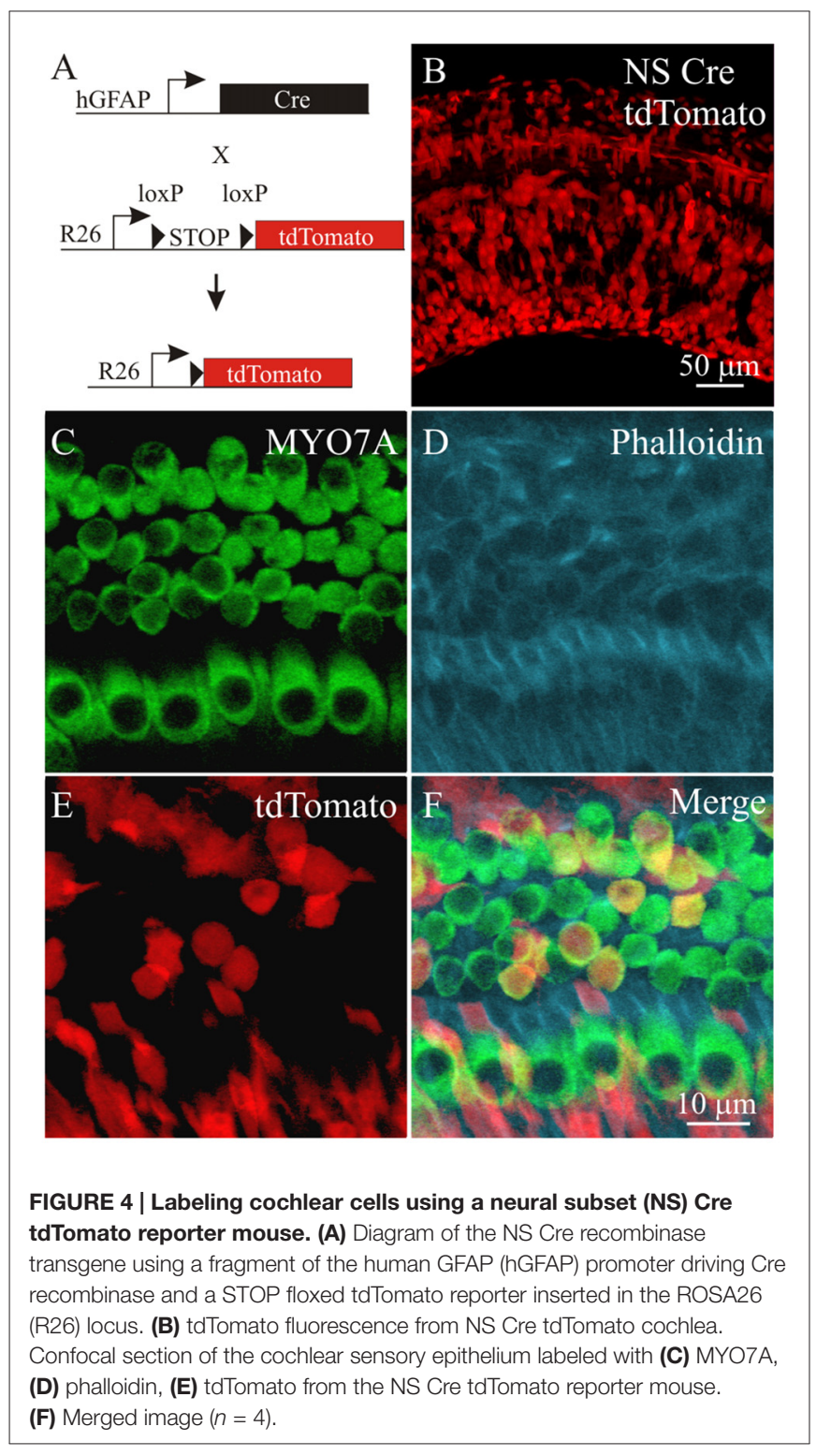

using a promoter fragment of the human GFAP promoter ablation to allow cell type specific knockout of Pten (Backman et al., 2001; Ljungberg et al., 2009). In these mice, expression of Cre recombinase under the ROSA26 promoter (R26) mediates excision of a loxP flanked STOP cassette and allows expression of the tdTomato red fluorescent protein (Madisen et al., 2010; Figure 4A). To confirm that NS Cre mice could mediate loxP excision in cochlear cell types, a NS Cre tdTomato reporter animal was generated to serve as a control. Fluorescent images of cochleae obtained from NS Cre tdTomato animals showed mosaic expression tdTomato fluorescence in many cochlear cell types (Figure 4B). To determine whether hair cells and supporting cells were labeled with tdTomato, cochlear explants were immmunostained using MYO7A antibodies (Figure 4C) and with phalloidin (Figure 4D). The tdTomato fluorescence (Figure 4E) marked MYO7A labeled hair cells as well as supporting cells that reside adjacent to both IHCs and OHCs
(Figure 4F). Analysis of sparsely labeled cells allowed us to determine the direct effect of activating PI3K signaling in supporting cells. These observed effects are cell autonomous and independent of activating PI3K signaling in surrounding cell types.

\section{Activation of PI3K Signaling Promotes Supporting Cell and Hair Cell Survival}

Next, we tested whether activation of PI3K signaling increased CHK1 phosphorylation in supporting cells to promote cell survival after cisplatin damage. The Pten conditional knockout allele was introduced into the NS Cre tdTomato animals to generate NS Cre Pten cKO tdTomato (Pten cKO) animals. These animals allowed activation of PI3K signaling by Pten deletion and fluorescently marked cochlear supporting cells with tdTomato expression. To induce ototoxic damage, cochlear explants from NS Cre tdTomato (control) and Pten cKO animals were treated with cisplatin. Cisplatin was removed after $24 \mathrm{~h}$ and the cochlea explant was replenished with fresh medium without cisplatin. Explants were allowed to recover for an additional 3 days before being fixed and subjected to immunolabeling (Figure 5A). Explants were immunostained for MYO7A and phalloidin to mark the hair cell bodies and the hair bundle. In cisplatin treated control cochlea, few MYO7A labeled hair cells with phalloidin labeled hair bundles and tdTomato marked supporting cells were observed (Figure 5B). The merged image showed disorganized surviving hair cells in the sensory epithelium. In contrast, cisplatin treatment of Pten cKO cochlea showed the presence of more MYO7A labeled hair cells with phalloidin labeled hair bundles surrounded by tdTomato expressing supporting cells (Figure 5C). To determine if the increased numbers of tdTomato labeled supporting cells could be due to increased CHK1 phosphorylation after cisplatin damage and activation of PI3K signaling, Pten cKO cochleae were immmunostained for $\mathrm{pCHK} 1$ after cisplatin damage. Increased nuclear pCHK1 could be observed in tdTomato labeled cells after cisplatin damage (Figure 5D). Increased pCHK1 levels could activate the DNA damage response and improve supporting cell survival.

To ascertain whether increased pCHK1 levels could promote supporting cell survival, we determined the density of surviving supporting cells after cisplatin treatment in control and Pten cKO animals. To quantify the presence of supporting cells after cisplatin damage, MYO7A- tdTomato+ cells were counted. A significant increase of supporting cell density from $79.4 \pm 2.3$ to $198.3 \pm 20.1$ cells $/ 0.1 \mathrm{~mm}^{2}\left(p<1 \times 10^{-2}\right)$ was observed when comparing controls to Pten cKO cochleae (Figure 5E). These results demonstrate that Pten deletion and subsequent activation of PI3K signaling increases the number of remaining supporting cells after cisplatin damage. As an internal control, MYO7A+ tdTomato+ hair cells were counted to determine whether activated PI3K signaling increases hair cell survival. A significant increase in the density of MYO7A+ tdTomato+ hair cells from $10.2 \pm 5.3$ to $56.8 \pm 8.1$ cells $/ 0.1 \mathrm{~mm}^{2}$ $\left(p<1 \times 10^{-3}\right)$ was observed when comparing controls to Pten cKO animals (Figure 5F). These results are consistent to previous 


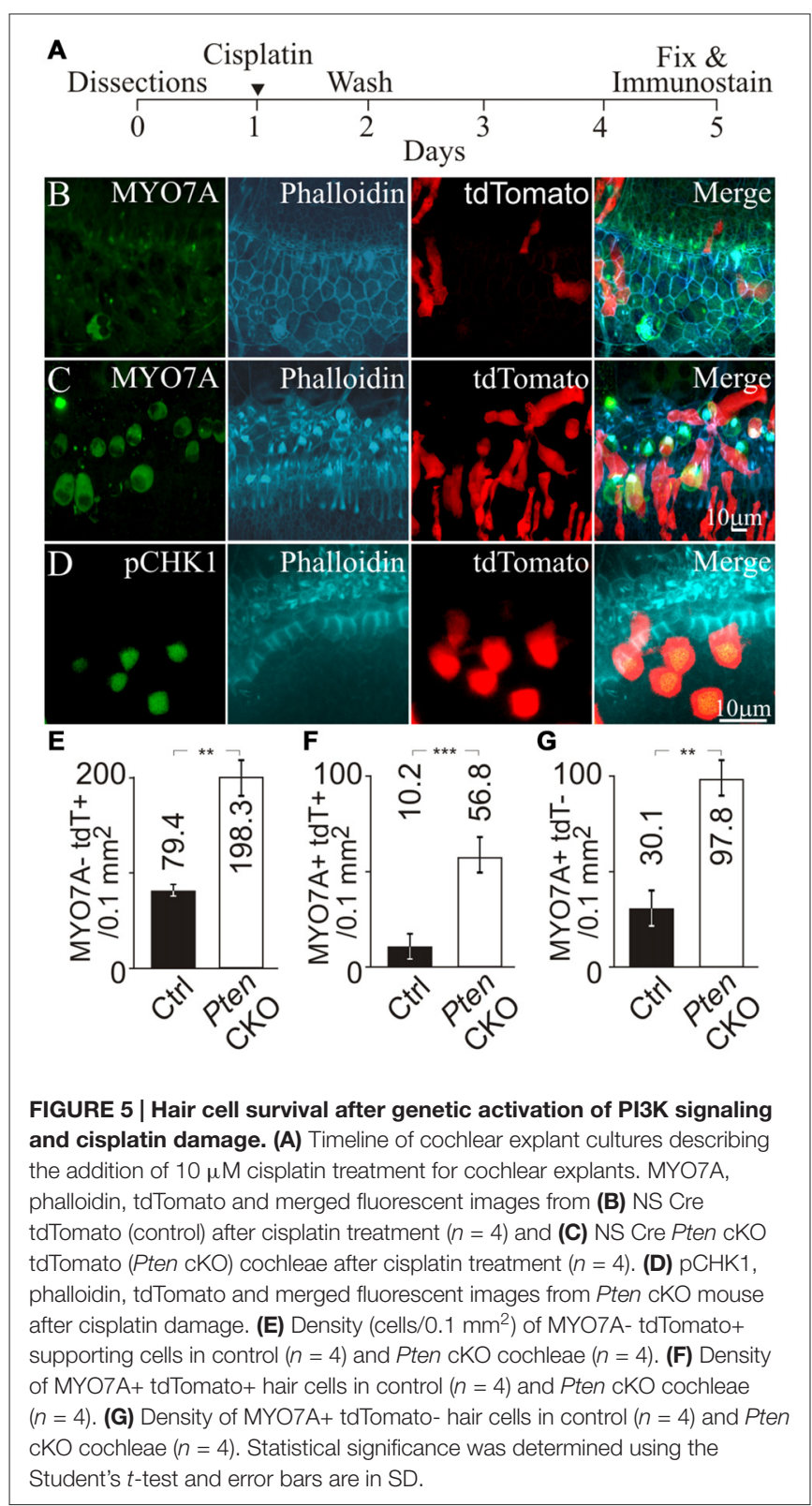

observations that activated PI3K signaling promotes hair cell survival (Jadali and Kwan, 2016). In addition, we also observed many MYO7A + tdTomato- hair cells. A significant increase in the number of MYO7A+tdTomato- hair cells from $30.1 \pm 8.3$ to $97.8 \pm 8.1$ cells $/ 0.1 \mathrm{~mm}^{2}\left(p<1 \times 10^{-2}\right)$ was observed when comparing controls to Pten cKO animals (Figure 5G). These results suggest that hair cell survival could not be explained by a simple cell autonomous effect of activated PI3K signaling and increased pCHK1 levels. Since there was an increased density of supporting cells after cisplatin damage, one possibility was that the presence of more supporting cells may indirectly improve hair cell survival after cisplatin damage. To test this hypothesis, we determined whether there was an increased number of supporting cells in the proximity of surviving hair cells.

\section{Surviving Hair Cells Reside in Close Proximity to Supporting Cells with Activated PI3K Signaling}

To test if increased hair cell survival correlates to the increased density of neighboring supporting cells, cochlea from control and Pten cKO animals were treated with cisplatin and labeled with MYO7A and phalloidin. To reduce the complexity of the analysis, regions along the cochlea lacking tdTomato hair cells were used. In these regions, MYO7A and phalloidin marked surviving hair cells while tdTomato labeled supporting cells. Confocal stacks were used to generate 3D renderings of the region of interest to ensure that only tdTomato supporting cells were present (Figure 6A). Using the 3D confocal image, the image was collapsed to generate 2D masks of hair cells (green) and supporting cells (red; Figure 6B). Using the combined masks, individual surviving hair cells (green) were identified before determining whether a supporting cell (red) resides next to the hair cell. All remaining neighboring cells in the field of view were marked in blue. In controls, $16.3 \pm 5.8 \%$ of MYO7A labeled hair cells reside adjacent to tdTomato supporting cells. In Pten cKO cochleae, $56.3 \pm 8.3 \%$ of MYO7A labeled hair cells reside next to a PI3K activated tdTomato supporting cells (Figure 6C). A significant increase in the percentage of hair cells adjacent to supporting cells was observed in Pten cKO cochleae compared to controls $\left(p<1 \times 10^{-2}\right)$. These data show that many supporting cells with activated PI3K signaling

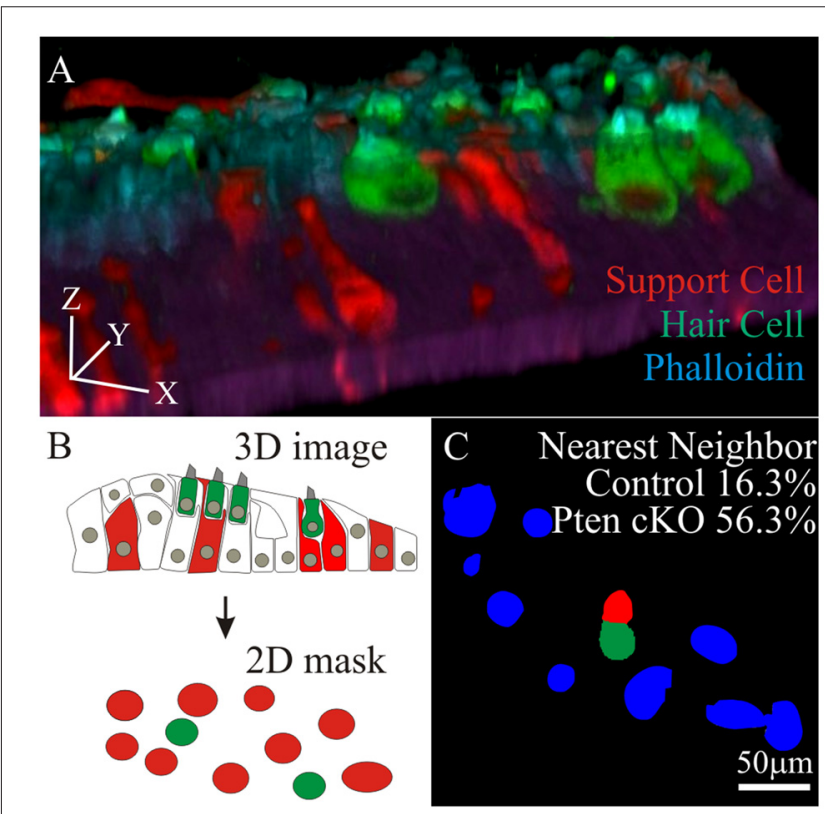

FIGURE 6 | Nearest neighbor analysis of supporting cell to surviving hair cells. (A) 3D rendering of a confocal stack with MYO7A and phalloidin labeled hair cells along with tdTomato labeled supporting cell (B) 3D images were compressed into a maximal intensity projection to generate a 2D mask for hair cells (green) and tdTomato labeled supporting cells (red). (C) Using the 2D masks, percent of surviving hair cells (green) that reside adjacent to supporting cells (red) were determined in control $(n=4)$ and Pten cKO cochleae $(n=4)$. All remaining cells in the field of view were labeled blue. 
reside in close proximity to surviving hair cells after cisplatin damage.

Next, we wanted to determine if the distribution of tdTomato marked supporting cells to surviving MYO7A hair cells in control and Pten cKO cochleae were different. To determine the distance between supporting cells and hair cells, an individual hair cell was identified and the distance to all supporting cells in the field of view was measured. To accomplish this, the $2 \mathrm{D}$ masks generated from tdTomato expressing supporting cells (Figure 7A) and MYO7A labeled hair cells (Figure 7B) were used to identify the different cell types. The masks were merged into a single image to show the location of hair cells relative to supporting cells (Figure 7C). To determine the spatial distribution between the hair cells and supporting cells, a cellular "interaction analysis" was performed (Helmuth et al., 2010). Centroid determination was done to convert masks that represent individual cell bodies into single points that correspond to the center of the mask. The distance from each centroid corresponding to a hair cell was measured to the centroid of all other supporting cells in the field of view (Figure 7D). The distribution of distances between a single hair cell and supporting cells were measured and plotted as a histogram. The number of interactions and the average distance between hair cell and supporting cells were determined (Figure 7E). The distribution of tdTomato labeled supporting cell relative to surviving hair cells contains information about potential oto-protective effects of supporting cells. The distribution of supporting cells to hair cells would show a stronger "cellular interaction" if supporting cells promoted hair cell survival. The "cellular interactions" between hair cells and supporting cells can be modeled as an interaction potential between the two sets of centroids. Using the centroids obtained from the cell masks, the observed distances between hair cells and supporting cells represented a distribution pattern. From the distribution pattern, a probability density function $q(d)$ of the observed nearest neighbor distances, was calculated to represent the likelihood of a "cellular interaction". The probability density function was then modeled as an interaction potential $p(d)$, to describe the likelihood that the distribution was due to "cellular interactions" (Figure 7F). The interaction potential $\mathrm{p}(\mathrm{d})$ was used to described the "cellular interaction" strength, to determine if objects of a specific distribution had an effect on each other (Figure 7G). A significant increase in interaction strength between tdTomato labeled supporting cell and surviving hair cells was observed in control $(1.29 \pm 0.4)$ compared to Pten cKO $(3.23 \pm 0.5)$ cochleae $\left(p<1 \times 10^{-2}\right.$; Figure $\left.7 \mathbf{H}\right)$. The increased interaction strength in Pten $\mathrm{cKO}$ cochlea relative to control suggests that the distribution of supporting cells with activated PI3K signaling are highly correlated to the increased numbers of surviving hair cells.

\section{DISCUSSION}

In this study, we showed increased phosphorylation of CHK1 after cisplatin damage and activation of PI3K signaling. Activation of CHK1 promotes survival of differentiating iMOP cells. Using cochlear explant cultures, increased phosphorylation of $\mathrm{CHK} 1$ after cisplatin damage and activation of PI3K signaling
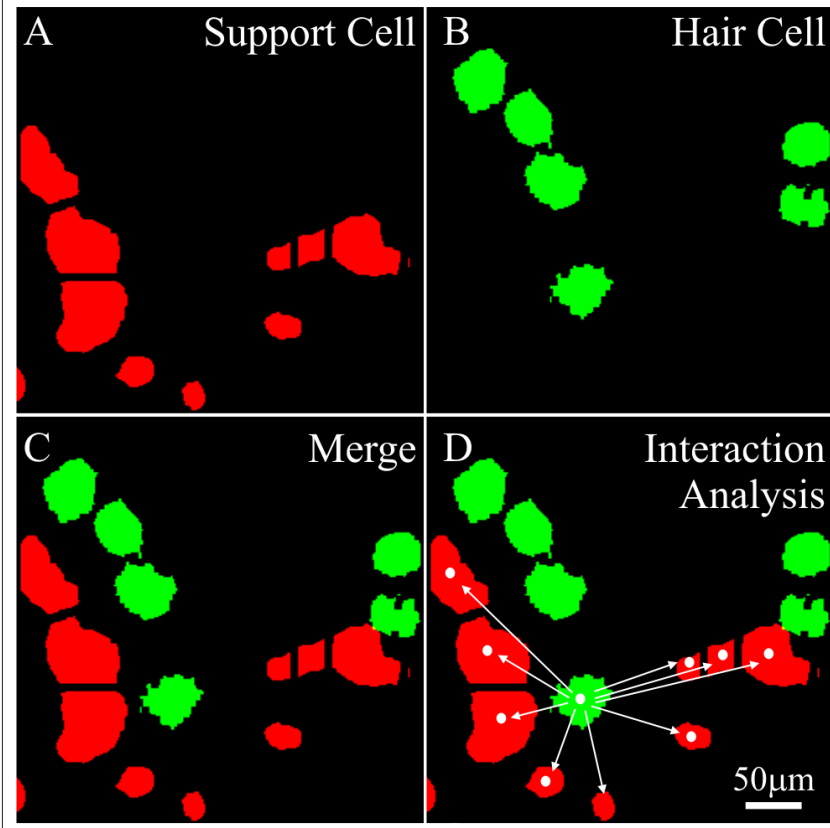

E

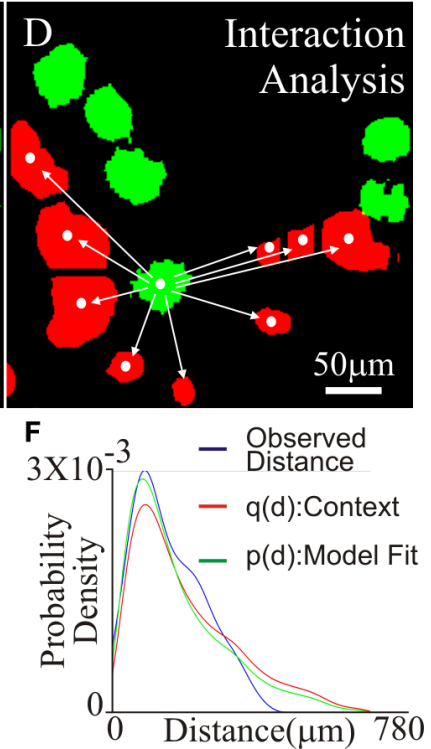

G

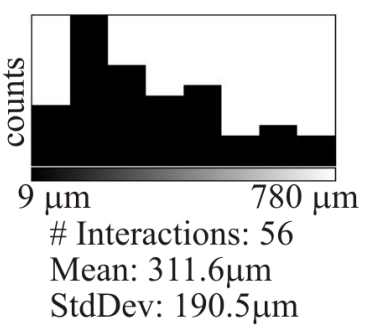

G

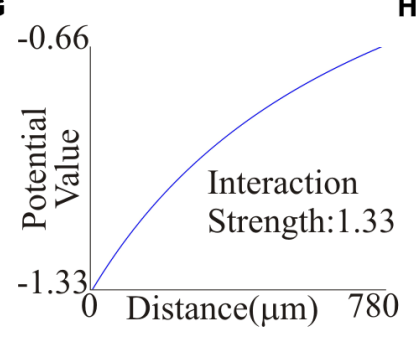

H

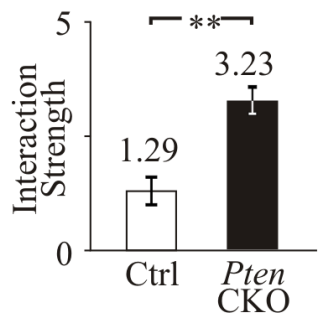

FIGURE 7 | Interaction strength of supporting cell and surviving hair cells. Region containing tdTomato+supporting cell and MYO7A+ tdTomato- hair cells were analyzed. (A) Supporting cell masks were generated from tdTomato labeled supporting cells (red). (B) Hair cell masks were generated from MYO7A labeled hair cells (green).

(C) Merged image of supporting cell and hair cell masks. (D) Centroid of hair cell and supporting cells were generated from masks. Distance between an individual hair cell centroid to all supporting cell centroids in the field of view was determined. (E) Number of cell interactions within a field of view and the mean distance between the centroid of a hair cell to multiple supporting cells was displayed in the histogram. (F) The observed distances between a hair cell and supporting cells were fitted into probability density, $p(d)$, and an interaction potential model, $q(d)$. (G) Interaction strength between hair cell and supporting cells was calculated from the interaction potential $q(\mathrm{~d})$. (H) Comparison of the interaction strength between surviving hair cells and control supporting cells $(n=10)$ or surviving hair cells and Pten cKO supporting cells $(n=10)$ after cisplatin treatment. Statistical significance was determined using the Student's $t$-test and error bars in SD. 


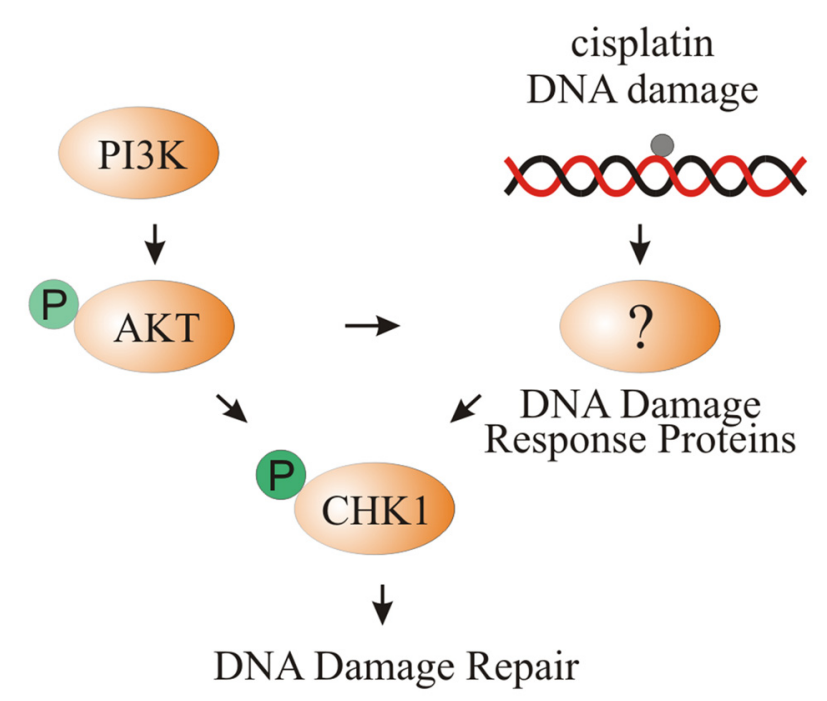

FIGURE 8 | Model of CHK1 phosphorylation through cisplatin damage and PI3K signaling. Activation of PI3K signaling either by bpV(HOpic) or Pten deletion results in increased AKT phosphorylation. DNA damage caused by cisplatin activates DNA damage response proteins that increase

pCHK1 levels. Activated AKT can directly or indirectly increase pCHK1 levels by activating the DNA damage response proteins. Together, PI3K activation and cisplatin-induced DNA damage results in increased pCHK1 to promote supporting cell survival.

was observed in supporting cells. We propose that increased PI3K signaling activates AKT which could directly phosphorylate $\mathrm{CHK} 1$ or indirectly increase pCHK1 levels through DNA damage response proteins such as ATR. Activation of CHK1 allows supporting cells to repair cisplatin-induced DNA damage (Figure 8).

\section{CHK1 Is Downstream of PI3K/AKT Signaling}

Our results suggest that activating the PI3K/AKT signaling pathway increases phosphorylation of $\mathrm{CHK} 1$ after cisplatin damage in supporting cells. These results are similar to reports in other systems where CHK1 is phosphorylated by AKT (Jin et al., 2005; Kurosu et al., 2013). Phosphorylation of CHK1 serves as a checkpoint protein that arrests cells at the G2/M phase of the cell cycle after DNA damage (Liu et al., 2000; Takai et al., 2000) and has also been implicated in DNA damage response (Sorensen et al., 2005; Shimada et al., 2008). Since supporting cells are post-mitotic, pCHK1 in supporting cells may contribute to the DNA damage response after cisplatin damage. We propose that pCHK1 can promote survival of cochlear supporting cells. Using differentiating iMOP cells, we showed that cisplatin-induced DNA damage results in phosphorylation of CHK1 at serine 345 using phospho-specific antibodies. Phosphorylation of serine 345 is essential for nuclear localization of CHK1 and response to DNA damage (Niida et al., 2007). Increased PI3K signaling as shown by increased $\mathrm{pAKT}$ in iMOP cells contributes to the phosphorylation of CHK1. In vivo, activation of $\mathrm{PI} 3 \mathrm{~K}$ signaling in tdTomato labeled supporting cells increased nuclear pCHK1 levels compared to surrounding cells. We propose that the additive effects of $\mathrm{CHK} 1$ phosphorylation may help enhance DNA damage response and increase supporting cell survival after cisplatin damage.

\section{AKT in Cochlear Supporting Cell Survival}

AKT (AKT1) belongs to a family of serine/threonine kinases that act downstream of PI3K and participates in a variety of cellular processes to play a critical role in cell survival (Datta et al., 1999). All three AKT isozymes are expressed in the cochlea (Brand et al., 2015). Mounting evidence shows that the PI3K/AKT signaling pathway plays a role in hair cell survival after exposure to ototoxic drugs. Inhibiting PI3K signaling in cochlear explants while treating with gentamicin showed increased hair cell loss compared to gentamicin exposure alone (Chung et al., 2006). Another study demonstrates that dexamethasone protects $\mathrm{HCs}$ against $\mathrm{TNF} \alpha$-initiated apoptosis by activating the PI3K/AKT signaling pathway (Haake et al., 2009). Exposure to simvastatin in cochlear explants activates AKT signaling and protects hair cells from gentamicin toxicity (Brand et al., 2011). These studies suggest that activation of PI3K/AKT signaling promotes hair cell survival. In addition to promoting hair cell survival, activation of PI3K signaling may also promote survival of supporting cells as observed by the increased density of supporting cells in Pten cKO cochleae compared to controls after cisplatin treatment. We propose that activation of $\mathrm{PI} 3 \mathrm{~K} / \mathrm{AKT}$ signaling contributes to supporting cell survival by CHK1 phosphorylation.

In cancer cells, several studies have established the involvement of AKT in contributing to cell survival by their acquired cisplatin resistance. These cancers cells include samples from ovarian, uterine, small-cell lung cancer, non-small-cell lung cancer and hepatoblastoma. Studies from these different cell lines and cancer cells suggest that cisplatin-induced DNA damage results in AKT phosphorylation of the pro-apoptotic factor Bcl2-associated agonist of cell death (BAD) at Ser136 to suppress cell death and promote cell survival (Datta et al., 1997; Hayakawa et al., 2000). In ovarian cancer cells, cisplatin-induced DNA damage results in activation of AKT and phosphorylation of X-linked inhibitor of apoptosis (XIAP). AKT phosphorylation of XIAP prevents XIAP ubiquitination and degradation in response to cisplatin to promote cell survival (Dan et al., 2004). In small-cell lung cancer cells, AKT phosphorylates the anti-apoptotic protein survivin to protect cells against cisplatin-induced cell death (Belyanskaya et al., 2005). In all, AKT phosphorylation of key molecules such as BAD, XIAP or survivin promotes cell survival after cisplatin damage. We propose that $\mathrm{CHK} 1$ is another downstream target of AKT in both iMOP cells and cochlear supporting cells after cisplatin damage.

\section{Increased Supporting Cell Survival Maintains Cochlear Cytoarchitecture and Indirectly Promotes Hair Cell Survival}

We noticed that after cisplatin damage, many hair cells could not be defined as either IHCs or OHCs due to the altered microarchitecture of the sensory epithelium. We propose that disorganization of hair cells may be due to supporting cell 
loss. Increased survival of supporting cells after activating PI3K signaling helps maintains hair cell organization in the sensory epithelium. In addition to changes in the cytoarchitecture of the sensory epithelium, supporting cell loss may indirectly contribute to hair cell loss. Our study showed increased density of PI3K activated supporting cells that reside in the vicinity of surviving hair cells compared to controls. The increased presence of supporting cells may provide additional oto-protection to hair cells. One mechanism for oto-protection is the release of HSP70 by supporting cells onto nearby hair cells (May et al., 2013). Another potential mechanism of oto-protection is cell-cell signlaing between hair cells and supporting cells. The ERBB signaling pathway is an example that cell types in the cochlea are constantly communicating with each other through cell-cell signaling. ERBB signaling has been observed between SGNs and supporting cells and presence of this signaling pathway is essential for survival of SGNs (Stankovic et al., 2004). Cell-cell signaling between supporting cells and hair cells may be another cellular mechanism that normally maintains hair cell viability. Ablation of inner border cells and inner phalangeal cells that flank IHCs causes loss of IHC and significantly impairs hearing in adult mice (Mellado Lagarde et al., 2014). The study suggests that cellular contact between supporting cells and IHCs may be essential for maintaining hair cell viability. We

\section{REFERENCES}

Backman, S. A., Stambolic, V., Suzuki, A., Haight, J., Elia, A., Pretorius, J., et al. (2001). Deletion of Pten in mouse brain causes seizures, ataxia and defects in soma size resembling Lhermitte-Duclos disease. Nat. Genet. 29, 396-403. doi: $10.1038 / \mathrm{ng} 782$

Belyanskaya, L. L., Hopkins-Donaldson, S., Kurtz, S., Simões-Wüst, A. P., Yousefi, S., Simon, H. U., et al. (2005). Cisplatin activates Akt in small cell lung cancer cells and attenuates apoptosis by survivin upregulation. Int. J. Cancer 117, 755-763. doi: 10.1002/ijc.21242

Bird, J. E., Daudet, N., Warchol, M. E., and Gale, J. E. (2010). Supporting cells eliminate dying sensory hair cells to maintain epithelial integrity in the avian inner ear. J. Neurosci. 30, 12545-12556. doi: 10.1523/JNEUROSCI.304210.2010

Brand, Y., Levano, S., Radojevic, V., Naldi, A. M., Setz, C., Ryan, A. F., et al. (2015). All Akt isoforms (Akt1, Akt2, Akt3) are involved in normal hearing, but only Akt 2 and Akt 3 are involved in auditory hair cell survival in the mammalian inner ear. PLoS One 10:e0121599. doi: 10.1371/journal.pone. 0121599

Brand, Y., Setz, C., Levano, S., Listyo, A., Chavez, E., Pak, K., et al. (2011). Simvastatin protects auditory hair cells from gentamicin-induced toxicity and activates Akt signaling in vitro. BMC Neurosci. 12:114. doi: 10.1186/1471-2202$12-114$

Cantley, L. C., and Neel, B. G. (1999). New insights into tumor suppression: PTEN suppresses tumor formation by restraining the phosphoinositide 3-kinase/AKT pathway. Proc. Natl. Acad. Sci. U S A 96, 4240-4245. doi: 10.1073/pnas. 96.8.4240

Chung, W.-H., Pak, K., Lin, B., Webster, N., and Ryan, A. (2006). A PI3K pathway mediates hair cell survival and opposes gentamicin toxicity in neonatal rat organ of corti. J. Assoc. Res. Otolaryngol. 7, 373-382. doi: 10.1007/s10162-006$0050-y$

Dan, H. C., Sun, M., Kaneko, S., Feldman, R. I., Nicosia, S. V., Wang, H. G., et al. (2004). Akt phosphorylation and stabilization of X-linked inhibitor of apoptosis protein (XIAP). J. Biol. Chem. 279, 5405-5412. doi: 10.1074/jbc. M312044200

Datta, S. R., Brunet, A., and Greenberg, M. E. (1999). Cellular survival: a play in three Akts. Genes Dev. 13, 2905-2927. doi: 10.1101/gad.13.22.2905 propose that after cisplatin damage, activation of PI3K signaling increases survival of supporting cells. Through several potential mechanisms including secretion of extracellular molecules or cell-cell signaling, the increased number of supporting cells promotes survival of nearby hair cells. The study implicates supporting cells as a cellular target for preventing hair cell loss.

\section{AUTHOR CONTRIBUTIONS}

$\mathrm{AJ}$ and KYK designed, performed the experiments and wrote the manuscript. Y-LMY helped with cell counts.

\section{FUNDING}

The work was supported in part by the Duncan and Nancy MacMillan Faculty Development Chair Endowment Fund (KYK) and National Institute on Deafness and Other Communication Disorders (NIH) R01 DC15000 (KYK).

\section{ACKNOWLEDGMENTS}

We would also like to acknowledge Theresa Choi for her expertise and help in flow cytometry.

Datta, S. R., Dudek, H., Tao, X., Masters, S., Fu, H., Gotoh, Y., et al (1997). Akt phosphorylation of BAD couples survival signals to the cell-intrinsic death machinery. Cell 91, 231-241. doi: 10.1016/s0092-8674(00) 80405-5

Doillon, C. J., Faure, R. L., Posner, B. I., and Savard, P. E. (1999). Peroxovanadium compounds as inhibitors of angiogenesis. Angiogenesis 3, 361-369. doi: 10.1023/A:1026577418765

Gómez-Casati, M. E., Murtie, J., Taylor, B., and Corfas, G. (2010). Cellspecific inducible gene recombination in postnatal inner ear supporting cells and glia. J. Assoc. Res. Otolaryngol. 11, 19-26. doi: 10.1007/s10162-0090191-x

Haake, S. M., Dinh, C. T., Chen, S., Eshraghi, A. A., and Van De Water, T. R. (2009). Dexamethasone protects auditory hair cells against TNF $\alpha$-initiated apoptosis via activation of PI3K/Akt and NFKB signaling. Hear. Res. 255, 22-32. doi: 10.1016/j.heares.2009.05.003

Hayakawa, J., Ohmichi, M., Kurachi, H., Kanda, Y., Hisamoto, K., Nishio, Y., et al. (2000). Inhibition of BAD phosphorylation either at serine 112 via extracellular signal-regulated protein kinase cascade or at serine 136 via Akt cascade sensitizes human ovarian cancer cells to cisplatin. Cancer Res. 60, 5988-5994.

Helmuth, J. A., Paul, G., and Sbalzarini, I. F. (2010). Beyond co-localization: inferring spatial interactions between sub-cellular structures from microscopy images. BMC Bioinformatics 11:372. doi: 10.1186/1471-2105-11-372

Jadali, A., and Kwan, K. Y. (2016). Activation of PI3K signaling prevents aminoglycoside-induced hair cell death in the murine cochlea. Biol. Open 5, 698-708. doi: 10.1242/bio.016758

Jadali, A., Zhichao, S., Alejandra, S. L., Alana, T.-R., and Kelvin, K. (2016). Initiating differentiation in immortalized multipotent otic progenitor cells. J. Vis. Exp. 107. doi: 10.3791/53692

Jiang, K., Pereira, E., Maxfield, M., Russell, B., Goudelock, D. M., and Sanchez, Y. (2003). Regulation of Chk1 includes chromatin association and 14-3-3 binding following phosphorylation on Ser-345. J. Biol. Chem. 278, 25207-25217. doi: 10.1074/jbc.M300070200

Jin, Z. H., Kurosu, T., Yamaguchi, M., Arai, A., and Miura, O. (2005). Hematopoietic cytokines enhance Chk1-dependent G2/M checkpoint activation by etoposide through the Akt/GSK3 pathway to inhibit apoptosis. Oncogene 24, 1973-1981. doi: 10.1038/sj.onc.1208408 
Kurosu, T., Nagao, T., Wu, N., Oshikawa, G., and Miura, O. (2013). Inhibition of the PI3K/Akt/GSK3 pathway downstream of BCR/ABL, Jak2-V617F, or FLT3-ITD downregulates DNA damage-induced Chk1 activation as well as G2/M arrest and prominently enhances induction of apoptosis. PLoS One 8:e79478. doi: 10.1371/journal.pone.0079478

Kwan, K. Y., Shen, J., and Corey, D. P. (2015). C-MYC transcriptionally amplifies SOX2 target genes to regulate self-renewal in multipotent otic progenitor cells. Stem Cell Reports 4, 47-60. doi: 10.1016/j.stemcr.2014.11.001

Liu, Q., Guntuku, S., Cui, X. S., Matsuoka, S., Cortez, D., Tamai, K., et al. (2000). Chk1 is an essential kinase that is regulated by Atr and required for the $G_{2} / M$ DNA damage checkpoint. Genes Dev. 14, 1448-1459.

Ljungberg, M. C., Sunnen, C. N., Lugo, J. N., Anderson, A. E., and D’Arcangelo, G. (2009). Rapamycin suppresses seizures and neuronal hypertrophy in a mouse model of cortical dysplasia. Dis. Model. Mech. 2, 389-398. doi: 10.1242/dmm. 002386

Madisen, L., Zwingman, T. A., Sunkin, S. M., Oh, S. W., Zariwala, H. A., Gu, H., et al. (2010). A robust and high-throughput Cre reporting and characterization system for the whole mouse brain. Nat. Neurosci. 13, 133-140. doi: 10.1038/ nn. 2467

May, L. A., Kramarenko, I. I., Brandon, C. S., Voelkel-Johnson, C., Roy, S., Truong, K., et al. (2013). Inner ear supporting cells protect hair cells by secreting HSP70. J. Clin. Invest. 123, 3577-3587. doi: 10.1172/JCI68480

Mellado Lagarde, M. M., Wan, G., Zhang, L., Gigliello, A. R., McInnis, J. J., Zhang, Y., et al. (2014). Spontaneous regeneration of cochlear supporting cells after neonatal ablation ensures hearing in the adult mouse. Proc. Natl. Acad. Sci. U S A 111, 16919-16924. doi: 10.1073/pnas.1408064111

Monzack, E. L., and Cunningham, L. L. (2013). Lead roles for supporting actors: critical functions of inner ear supporting cells. Hear. Res. 303, 20-29. doi: 10.1016/j.heares.2013.01.008

Monzack, E. L., May, L. A., Roy, S., Gale, J. E., and Cunningham, L. L. (2015). Live imaging the phagocytic activity of inner ear supporting cells in response to hair cell death. Cell Death Differ. 22, 1995-2005. doi: 10.1038/cdd.2015.48

Niida, H., Katsuno, Y., Banerjee, B., Hande, M. P., and Nakanishi, M. (2007). Specific role of Chk1 phosphorylations in cell survival and checkpoint activation. Mol. Cell. Biol. 27, 2572-2581. doi: 10.1128/mcb. 01611-06

Ramírez-Camacho, R., García-Berrocal, J. R., Buján, J., Martín-Marero, A., and Trinidad, A. (2004). Supporting cells as a target of cisplatin-induced inner ear damage: therapeutic implications. Laryngoscope 114, 533-537. doi: 10.1097/00005537-200403000-00027

Rybak, L. P., Mukherjea, D., Jajoo, S., and Ramkumar, V. (2009). Cisplatin ototoxicity and protection: clinical and experimental studies. Tohoku J. Exp. Med. 219, 177-186. doi: 10.1620/tjem.219.177

Schacht, J., Talaska, A. E., and Rybak, L. P. (2012). Cisplatin and aminoglycoside antibiotics: hearing loss and its prevention. Anat. Rec. (Hoboken) 295, 1837-1850. doi: 10.1002/ar.22578

Schmid, A. C., Byrne, R. D., Vilar, R., and Woscholski, R. (2004). Bisperoxovanadium compounds are potent PTEN inhibitors. FEBS Lett. 566, 35-38. doi: 10.1016/j.febslet.2004.03.102
Shimada, M., Niida, H., Zineldeen, D. H., Tagami, H., Tanaka, M., Saito, H., et al. (2008). Chk1 is a histone $\mathrm{H} 3$ threonine 11 kinase that regulates DNA damage-induced transcriptional repression. Cell 132, 221-232. doi: 10.1016/j. cell.2007.12.013

Siddik, Z. H. (2003). Cisplatin: mode of cytotoxic action and molecular basis of resistance. Oncogene 22, 7265-7279. doi: 10.1038/sj.onc.1206933

Sorensen, C. S., Hansen, L. T., Dziegielewski, J., Syljuasen, R. G., Lundin, C. Bartek, J., et al. (2005). The cell-cycle checkpoint kinase Chk1 is required for mammalian homologous recombination repair. Nat. Cell Biol. 7, 195-201. doi: $10.1038 /$ ncb 1212

Stankovic, K., Rio, C., Xia, A., Sugawara, M., Adams, J. C., Liberman, M. C., et al. (2004). Survival of adult spiral ganglion neurons requires erbB receptor signaling in the inner ear. J. Neurosci. 24, 8651-8661. doi: 10.1523/JNEUROSCI.0733-04.2004

Takai, H., Tominaga, K., Motoyama, N., Minamishima, Y. A., Nagahama, H., Tsukiyama, T., et al. (2000). Aberrant cell cycle checkpoint function and early embryonic death in $C h k 1^{(-/-)}$mice. Genes Dev. 14, 1439-1447.

van Ruijven, M. W., de Groot, J. C., Hendriksen, F., and Smoorenburg, G. F. (2005). Immunohistochemical detection of platinated DNA in the cochlea of cisplatin-treated guinea pigs. Hear. Res. 203, 112-121. doi: 10.1016/j.heares. 2004.12.007

Vermes, I., Haanen, C., Steffens-Nakken, H., and Reutelingsperger, C. (1995). A novel assay for apoptosis. Flow cytometric detection of phosphatidylserine expression on early apoptotic cells using fluorescein labelled Annexin V. J. Immunol. Methods 184, 39-51. doi: 10.1016/0022-1759(95)00072-i

Vlahos, C. J., Matter, W. F., Hui, K. Y., and Brown, R. F. (1994). A specific inhibitor of phosphatidylinositol 3-kinase, 2- (4-morpholinyl)-8-phenyl-4H-1 benzopyran-4-one (LY294002). J. Biol. Chem. 269, 5241-5248.

Wan, G., Corfas, G., and Stone, J. S. (2013). Inner ear supporting cells: rethinking the silent majority. Semin Cell Dev. Biol. 24, 448-459. doi: 10.1016/j.semcdb. 2013.03.009

Wang, D., and Lippard, S. J. (2005). Cellular processing of platinum anticancer drugs. Nat. Rev. Drug Discov. 4, 307-320. doi: 10.1038/nrd1691

Zhang, Y., and Hunter, T. (2014). Roles of Chk1 in cell biology and cancer therapy. Int. J. Cancer 134, 1013-1023. doi: 10.1002/ijc.28226

Zhao, H., and Piwnica-Worms, H. (2001). ATR-mediated checkpoint pathways regulate phosphorylation and activation of human Chk1. Mol. Cell. Biol. 21, 4129-4139. doi: 10.1128/mcb.21.13.4129-4139.2001

Conflict of Interest Statement: The authors declare that the research was conducted in the absence of any commercial or financial relationships that could be construed as a potential conflict of interest.

Copyright (C) 2017 Jadali, Ying and Kwan. This is an open-access article distributed under the terms of the Creative Commons Attribution License (CC BY). The use, distribution or reproduction in other forums is permitted, provided the original author(s) or licensor are credited and that the original publication in this journal is cited, in accordance with accepted academic practice. No use, distribution or reproduction is permitted which does not comply with these terms. 